\title{
Toxoplasma gondii EN VICUÑAS DE LA RESERVA NACIONAL DE PAMPA GALERAS
}

\author{
Mijail Zuzunaga D. ${ }^{1}$, Amanda Chávez V. ${ }^{2}$, Olga Li E. ${ }^{3}$ y Roberto Evaristo R. ${ }^{4}$
}

\section{Abstract}

The definitive host of the protozoan Toxoplasma gondii is the feline and intermediate hosts are a wide number of species, such as sheep, goats, pigs, birds and human. This protozoan is worldwide distributed, has zoonotic connotations, and cause reproductive problems in livestock, especially in sheep. The objective of the present study was to determine the seroprevalence of $T$. gondii in vicunas at the National Reserve of Pampa Galeras, located in Ayacucho, Peru. A total of 191 vicunas, both males and females, were blood sampled and serum was analyzed by the indirect immunofluorescent antibody test (IFAT). The resulting seroprevalence was $5.8 \pm 3.3 \%$, without statistical differences due to sex and age factors. The present study demonstrated the presence of $T$. gondii infection for in vicunas of the National Reserve of Pampa Galeras.

Key words: toxoplasmosis, vicuna, serology, antibody

\section{Resumen}

El Toxoplasma gondii es una parásito protozoario que tiene como hospedero definitivo al felino y como hospederos intermediarios a un amplio rango de especies incluyendo ovinos, caprinos, porcinos, aves y humanos. Este protozoo está distribuido a nivel mundial, tiene implicancia zoonótica y es causante de problemas reproductivos en el ganado, principalmente en el ovino. El objetivo del presente estudio fue determinar la seroprevalencia de T. gondii en vicuñas de la Reserva Nacional de Pampa Galeras, Ayacucho, Perú. Se muestrearon 191 vicuñas, entre machos y hembras, y los sueros se analizaron con la prueba de inmunofluorescencia indirecta. La seroprevalencia obtenida fue de $5.8 \pm 3.3 \%$, no observándose diferencias estadísticas significativas por efecto de sexo y grupo etáreo. El presente estudio demuestra la infección por T. gondii en vicuñas de la Reserva Nacional de Pampa Galeras.

Palabras clave: toxoplasmosis, vicuña, serología, anticuerpo

\author{
${ }^{1}$ Práctica privada \\ ${ }^{2}$ Laboratorio de Microbiología y Parasitología Veterinaria, FMV-UNMSM \\ E-mail: a chavez.g@hotmail.com \\ ${ }^{3}$ Laboratorio de Patología Clínica, FMV-UNMSM \\ ${ }^{4}$ Clínica de Animales Mayores, FMV-UNMSM
}


INTRODUCCIÓN

La vicuña es una de las cuatro especies de camélidos sudamericanos (CSA) que al igual que el guanaco, permanece en estado silvestre. El valor productivo de la vicuña se ha incrementado notablemente en los últimos años debido al aumento de la cotización de su fibra en el mercado internacional; sin embargo, los estudios realizados sobre problemas de tipo infeccioso y parasitario en esta especie son escasos.

El Toxoplasma gondii, parásito protozoario del Phylum Apicomplexa, tiene como hospedero definitivo al felino (doméstico o silvestre) y como hospedero intermediario a un amplio rango de especies (ovino, caprino, bovino, porcino, equino, felinos, aves y humanos, entre otros). Es de gran importancia a nivel mundial, no sólo por causar problemas de tipo reproductivo en el ganado (abortos, momificación fetal, mortinatos y nacimientos de crías débiles), especialmente en ovinos y caprinos; sino también por ser una enfermedad zoonótica de gran implicancia en la salud humana, tanto de niños como en adultos que tienen comprometido el sistema inmunológico (Martín-Hernández y GarcíaIzquierdo, 2003).

Estudios realizados en vicuñas sobre $T$. gondii son escasos en el Perú. Se dispone de un reporte que señala una prevalencia del $15 \%$ en Puno (Pastor et al., 2003), pero no se tiene datos sobre la implicancia y distribución de este agente en otras zonas del país. Por otro lado, estudios de prevalencia en otras especies de CSA señalan valores que varían entre 24 a 50\% en alpacas (Góngora, 1992; Leguía et al; 1987) y de 10 a $57 \%$ en llamas (Marcas et al., 2004; Saravia et al., 2004). Es así que se diseñó el presente estudio para determinar la seroprevalencia de $T$. gondii en vicuñas de de la Reserva Nacional de Pampa Galeras.
Materiales Y Métodos

\section{Lugar de estudio y animales}

El estudio se llevó a cabo en la Reserva Nacional de Pampa Galeras, ubicada en el distrito de San Cristóbal, provincia de Lucanas, departamento de Ayacucho, a una altura entre los 3,800 y 5,000 msnm, y con una temperatura promedio anual de $5^{\circ} \mathrm{C}$. La zona presenta áreas que se encuentran densamente cubiertas de ichu y posee una extensión de 6,500 hectáreas.

La toma de muestras de sangre se hizo durante la tradicional captura de vicuñas, el "Chaku", entre los meses de junio a noviembre del 2003 y en mayo del 2004.

Se calculó un tamaño muestral mínimo de 191 a través de la fórmula de proporciones en poblaciones finitas (Daniel, 1996). La estratificación de las muestras colectadas se hizo en función a las variables sexo y edad, teniendo en cuenta su distribución poblacional. Se consideró como crías, a los animales menores de 9 meses; juveniles, a aquellos entre 9 y 18 meses; y adultos, a partir de los 18 meses de edad (Zúñiga, 1998).

\section{Toma de muestra y análisis de laboratorio}

Las muestras de sangre se obtuvieron por punción de la vena yugular. El suero resultante se trasvasó a microtubos de $2 \mathrm{ml} \mathrm{y}$ se guardaron en congelación $\left(-20{ }^{\circ} \mathrm{C}\right)$ hasta su análisis en el Laboratorio de Parasitología de la Facultad de Medicina Veterinaria de la Universidad Nacional Mayor de San Marcos, Lima.

Las muestras se analizaron mediante la prueba de inmunofluorescencia indirecta (IFI), según lo descrito por Chávez et al. (2005). Se empleó la dilución de 1:200, utilizando como antígeno taquizoitos formolizados (cepa ME-49) y un conjugado comercial anti IgG de llama (Lab. VMRD), considerándose como muestras positivas las que presentaban fluorescencia completa del taquizoito. 


\section{Análisis de datos}

Los resultados de seroprevalencia a $T$. gondii se expresaron en forma porcentual (Thrusfield, 1990), con su respectivo intervalo de confianza (Armitage y Berry, 1987).

\section{Resultados y Discusión}

La seroprevalencia de $T$. gondii fue de $5.8 \pm 3.3 \%$ (Cuadro 1). Esta prevalencia es baja si se compara con resultados obtenidos en otros estudios; posiblemente debido a factores tales como la técnica empleada, zona geográfica, presencia de hospederos definitivos y sistema de crianza. Por ejemplo, se dispone de un reporte de $15 \%$ de prevalencia en vicuñas del INIA-Puno utilizando la técnica de hemoaglutinación indirecta (Pastor et al., 2003). En el presente estudio, el uso de la técnica de IFI con una dilución del suero en $1 / 200$, reduciría la sobreestimación de la infección que se obtendría con la dilución de 1/ 50, la cual suele ser utilizada en la mayoría de las evaluaciones epidemiológicas en CSA (Chávez et al., 2005).

Así mismo, el área geográfica y el sistema de crianza pueden influir en los resultados. Este estudio se realizó en una reserva nacional con un área de 6,500 ha, donde sólo se crían vicuñas, mientras que en el estudio de Pastor et al (2003), las vicuñas estaban en un sistema de crianza en pastoreo mixto con otras especies de CSA, donde se ha reportado 10 y $36 \%$ de prevalencia de $T$. gondii en llamas y alpacas, respectivamente (Saravia $e t$ al., 2004; Ramírez, 2005). Factores adicionales como temperatura, humedad y altitud de la sierra sur del país podrían ser más favorables para la supervivencia de la forma infectiva del parásito (ooquiste).

La presencia de hospederos definitivos en la zona de estudio son escasos, ya que las vicuñas son criadas de forma extensiva en altitudes que varían de 3,800 a 4,800 msnm (Zúñiga, 1998). La presencia de gatos domésticos en esas altitudes es poco probable por encontrarse alejadas de zonas pobladas; no obstante, la presencia de felinos silvestres como el puma es frecuente y estos podrían actuar como diseminadores de ooquistes a través de las heces. El puma acostumbra acercarse a los bofedales o puquiales con el fin de beber agua, y a su vez, las vicuñas llegan a estas zonas con el fin de alimentarse, ya que las zonas de puquiales son las áreas con mejores pastos por las condiciones favorables de humedad.

La baja prevalencia hallada en vicuñas, a diferencia de otras especies de CSA, pudo deberse a diferencias en el manejo y sistema de crianza. En alpacas se reportan prevalencias de 24 a 50\% (Gómez et al., 2003; Góngora, 1992; Leguía et al., 1987; Ramírez, 2005; Suárez et al., 2004). La alpaca, al ser usada en la producción de fibra es sometida a un mayor estrés al recibir un manejo más exigente durante las diversas faenas de manejo (empadre, esquila y dosificaciones, entre otras), posibilitando la disminución de sus defensas inmunitarias y la exposición a cualquier tipo de infección (Tizard, 1995); por otro lado, las vicuñas, por ser animales silvestres, están sujetos a menor estrés (Zúñiga, 1998).

La prevalencia a $T$. gondii en hembras fue ligeramente superior a la encontrada en machos (7.2 y $4.3 \%$, respectivamente), pero esta diferencia no fue estadísticamente significativa (Cuadro 1). No se detectaron animales reactores en el grupo de crías, a diferencia de juveniles y adultos en los cuales se observaron prevalencias de 7.7 y $5.3 \%$, respectivamente, aunque sin diferencia estadística significativa entre edades (Cuadro 1). La ausencia de reactores entre las crías pudo deberse a su escaso número y a la menor posibilidad de ingerir el ooquiste del parásito por encontrase en fase de lactación. 
Cuadro 1. Seroprevalencia de T. gondii en vicuñas de la Reserva Nacional de Pampa Galeras, Ayacucho (2003)

\begin{tabular}{lllcc}
\hline \multirow{2}{*}{ Variable } & Animales muestreados & \multicolumn{2}{c}{ Animales seropositivos } \\
\cline { 3 - 5 } & & & $\mathrm{N}^{\mathrm{o}}$ & $\% \pm \mathrm{IC}$ \\
\hline Sexo & & & & \\
& Macho & 94 & 4 & $4.3 \pm 4.1$ \\
& Hembra & & 7 & $7.1 \pm 5.1$ \\
Edad & & 18 & & - \\
& Crías & 78 & 0 & $7.7 \pm 5.9$ \\
& Juveniles & 95 & 6 & $5.3 \pm 4.6$ \\
& Adultos & 191 & 5 & $5.8 \pm 3.3$ \\
\hline Total & & & 11 & \\
\hline
\end{tabular}

IC: Intervalo de confianza del 95\%

\section{Conclusiones}

- Las vicuñas de la Reserva Nacional de Pampa Galeras han estado expuestas al Toxoplasma gondii.

- La seroprevalencia encontrada fue baja $(5.8 \pm 3.3 \%)$, y no estuvo afectada por las variables sexo y grupo etáreo.

\section{Literatura CitadA}

1. Armitage, P.; G. Berry. 1987. Statistical methods in medical research. $2^{\text {nd }}$ ed. $p$ 115-120. Blackwell Scientific Publications. UK.

2. Chávez-Velásquez, A.; G. AlvarezGarcía; M. Gómez-Bautista; E. Casas-Astos; E. Serrano-Martínez; L.M. Ortega-Mora. 2005. Toxoplasma gondii in adult llamas (Lama glama) and vicunas (Vicugna vicugna) in the Peruvian Andean region. Vet. Parasitol. 130: 93-97.
3. Daniel, W. 1996. Bioestadística: base para el análisis de las ciencias de la salud. $3^{\mathrm{a}}$ ed. p 202-209. Limusa. México.

4. Gómez, O.; A. Chávez; E. Casas; E. Serrano; O. Cárdenas. 2003. Determinación de la seroprevalencia de toxoplasmosis en alpacas y llamas en la estación experimental INIA-Puno. Rev. Inv. Vet., Perú 14: 49-53.

5. Góngora, M. 1992. Prevalencia de anticuerpos contra Toxoplasma gondii en las comunidades alpaqueras de Vilcallamas, Bajo Llallagua, Huanacayama y Llusta. Tesis de Médico Veterinario Zootecnista. Facultad de Medicina Veterinaria y Zootecnia, Univ. Nacional del Altiplano. Puno. 47 p.

6. Leguía, G.; H. Samamé; C. Guerrero; M. Rojas; A. Nuñez. 1987. Prevalencia de anticuerpos contra $T$. gondii el alpacas. Rev. Cienc. Vet. 3: 19-21.

7. Marcas, G; A. Chávez; E. Casas; W. García; N. Falcón. 2004. Seroprevalencia de $T$. gondii en llamas de dos fundos ganaderos de la provincia de Melgar, Puno. Rev. Inv. Vet., Perú 15: 44-48. 
8. Martín-Hernández, I.; S. García-Izquierdo. 2003. Toxoplasmosis en el hombre. Bioquimia 28: 19-27.

9. Pastor, J.; A. Chávez; E. Casas; E. Serrano. 2003. Seroprevalencia de $T$. gondii en vicuñas de Puno. Rev. Inv. Vet., Perú 14: 79-82.

10. Ramírez, J. 2005. Seroprevalencia de T. gondii en alpacas de la provincia de Canchis-Cusco. Tesis de Médico Veterinario. Facultad de Medicina Veterinaria, Univ. Nacional Mayor de San Marcos. Lima. $67 \mathrm{p}$.

11. Saravia, M.; A. Chávez; E. Casas; N. Falcón; W. Pinto. 2004. Seroprevalencia de $T$. gondii en llamas de una empresa pecuaria en Melgar, Puno. Rev. Inv. Vet., Perú 15: 49-55.

12. Suárez, F.; W. Flores; A. Chávez; H. Rivera; W. Huanca. 2004. Toxoplasmosis en alpacas de la sierra altoandina. Rev. Inv. Vet., Perú 15: 170173.

13. Tizard, I. 1995. Inmunología veterinaria. $4^{a}$ ed. p 238-239. Ed. Interamericana McGraw-Hill. México.

14. Zuñiga, M. 1998. Manual calendarizado de actividades para el manejo de vicuñas. Consejo Nacional de Camélidos Sudamericanos (CONACS). Programa de Camélidos Silvestres. Lima, Perú. 